\title{
KONSEP SPIRITUAL MARKETING DALAM PEMASARAN PROGRAM STUDI EKONOMI SYARIAH FAKULTAS EKONOMI DAN BISNIS ISLAM UNIVERSITAS SURYAKANCANA
}

Uus Ahmad Husaeni ${ }^{1 *}$, Huzni Farhany ${ }^{2}$, Nina Nurkomalasari ${ }^{3}$, Farid Faisal ${ }^{4}$

${ }^{1234}$ Fakultas Ekonomi dan Bisnis Islam Universitas Suryakancana

*Corresponding Author email: uusahmadhusaeni@unsur.ac.id

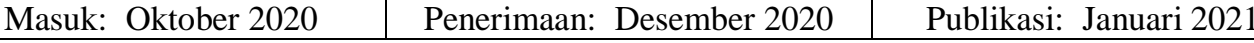

Tujuan penelitian ini adalah untuk menganalisis konsep spiritual marketing dalam pemasaran prodi Ekonomi Syariah Fakultas Ekonomi dan Bisnis Islam Universitas Suryakancana yang pada akhirnya terjadi peningkatan jumlah mahasiswa dari tahun ke tahun. Metode penelitian ini menggunakan penelitian kepustakaan (library research). Adapun metode pengolahan data yang digunakan adalah dengan mengumpulkan data-data yang diperoleh dari penelitian lapangan, peraturan-peraturan dan buku-buku yang diolah serta dianalisis dengan menggunakan metode kualitatif. Kesimpulan dari penelitian ini yaitu implementasi spiritual marketing dalam upaya memasarkan prodi-prodi pada Fakultas Ekonomi dan Bisnis Islam Universitas Suryakancana sangat dianjurkan, mengingat dampak dari penerapannya sangat menguntungkan bagi peningkatan jumlah mahasiswa. Implementasi konsep spiritual marketing pada akhirnya akan menumbuhkan rasa loyalitas dan trust pada benak masyarakat akan kredibilitasnya terhadap FEBI. Adapun keuntungan dalam jangka panjang, FEBI akan memperoleh wallet share dari siklus spiritual marketing yang dapat digunakan sebagai modal pengembangan ekonomi syariah dimasa yang akan datang.

Kata Kunci: Spiritual marketing; Fakulas Ekonomi dan Bisnis Islam; wallet share; mind; market share

\begin{abstract}
The purpose of this study is to analyze the concept of spiritual marketing in the marketing of the Islamic Economics Department which in turn has increased the number of students from year to year. This research method uses library research. The data processing method used is to collect data obtained from field research, regulations and books which are processed and analyzed using qualitative methods. The conclusion of this research is that the implementation of spiritual marketing in an effort to market of Islamic Economic department at the Faculty of Islamic Economics and Business (FEBI), Suryakancana University is highly recommended, considering the impact of its application is very beneficial for increasing the number of students. The implementation of the spiritual marketing concept will ultimately foster a sense of loyalty and trust in the minds of the public regarding its credibility towards FEBI. As for the long-term benefits, FEBI will get a wallet share from the spiritual marketing cycle which can be used as capital for the development of the Islamic economy in the future.
\end{abstract}

Keywords: Spiritual marketing; Islamic Economics and Business Faculty; wallet share; mind; market share. 


\section{A. PENDAHULUAN}

Perkembangan Ekonomi Syariah di dunia dimulai dengan pendirian bank syariah dan kemudian diikuti oleh pendirian lembaga keuangan syariah. Pertumbuhan yang sangat pesat mendorong para akademisi di berbagai perguruan tinggi melakukan kajian lebih mendalam dalam berbagai bentuk penelitian, diskusi, bahkan mengembangkannya dalam bentuk program studi baik sarjana hingga doktoral. Dengan teknologi pengajaran modern, mengadopsi sistem pembelajaran barat dan go international juga mempelajari dua keilmuan (ekonomi syariah dan konvensional) menjadikan program studi Ekonomi Syariah mempunyai point of different di bandingkan dengan program studi yang lain.

Universitas Suryakancana merupakan universitas terbesar yang berada di wilayah Kabupaten Cianjur dengan total jumlah mahasiswa mencapai 5.000 orang. Universitas Suryakancana memiliki lima fakultas dan program pascasarjana diantaranya yaitu Fakultas Ekonomi dan Bisnis Islam (FEBI). FEBI merupakan fakultas termuda yang berada dalam lingkungan civitas akademika Universitas Suryakancana. Pada tahun 2016, Fakultas Agama Islam (FAI) bertransformasi menjadi Fakultas Ekonomi dan Bisnis Islam (FEBI) dengan 3 prodi yaitu: Ekonomi Syariah, Perbankan Syariah, dan Manajemen Pendidikan Islam. Dan saat ini menambah program studi baru yaitu Akuntansi Syariah.

Dengan bertransformasinya FAI menjadi FEBI merupakan salah satu cara melakukan perluasan merk, jika dilihat dari segmen ekonomi, sehingga diharapkan dengan adanya transformasi ini berimbas pada peningkatan jumlah mahasiswa, kualitas pembelajaran dan peningkatan kesejahteraan dosen.

Secara umum, visi, misi dan tujuan Fakultas Ekonomi dan Bisnis Islam ingin menjadi institusi pendidikan dengan standar mutu tinggi yang terbuka, akuntabel, terakreditasi dan mandiri. Visi dan Misi Unsur yang pada tahun 2031 ingin menjadi World Class University merupakan peluang bagi semua fakultas termasuk didalamnya Fakultas Ekonomi dan Bisnis Islam (FEBI) yang notabene merupakan fakultas baru untuk membenahi diri semaksimal mungkin menuju manajemen yang lebih profesional dan kinerja yang lebih baik, sesuai dengan tujuan serta visi dan misi yang telah dicanangkan. 
Konsep yang diberikan untuk memasarkan Fakultas Ekonomi dan Bisnis Islam (FEBI) kepada masyarakat belum terbukti ampuh, hal ini tercermin dengan jumlah mahasiswa yang memilih prodi-prodi pada FEBI masih sedikit. Bila dilihat secara objektif, FEBI mempunyai prospek yang sangat bagus, karena dalam sistem pengajarannya, mahasiswa diajarkan pada dua disiplin ilmu (konvensional dan syariah) dan penekanan etika, moral, dan spiritual pada diri mahasiswa. Sistem seperti ini dapat memberikan point of different bagi mahasiswa FEBI di bandingkan dengan jurusan lain.

Maka dari itu, FEBI dianjurkan untuk mengimplementasikan konsep etika, moral, dan spiritual yang ada pada diri mahasiswa selama masa pembelajaran untuk memasarkan prodi-prodi FEBI kepada masyarakat. Atau lebih dikenal dengan istilah spiritual marketing. Dengan kata lain, penelitian ini ingin mengetahui seberapa besar dampak implementasi konsep spiritual marketing untuk memasarkan prodi-prodi FEBI terhadap jumlah calon mahasiswa yang memilih prodi-prodi FEBI sebagai pilihan pertama dan utama. Perlu diketahui bahwa sistem pemasaran ini sangat berbeda dengan sistem pemasaran yang lain. Dalam spiritual marketing, pemasar dibekali oleh tiga konsep kombinasi penting, antara lain: kecerdasan intelektual, kecerdasan emosional, dan memasukkan value emosional dalam berinteraksi dengan orang lain.

\section{B. METODE PENELITIAN}

Penelitian ini bersifat deskriptif analitis dengan pendekatan penelitian kepustakaan (library research) dilakukan dengan maksud agar peneliti dapat menggali dan mengkaji secara mendalam data-data yang berkaitan dengan permasalahan yang diteliti yakni menggunakan data sekunder yang diperoleh melalui bahan-bahan kepustakaan. Alat penelitian kepustakaan berupa studi dokumen yaitu mempelajari dan meneliti berbagai sumber kepustakaan yang memberikan penjelasan terhadap objek penelitian. Metode pengolahan data yang digunakan adalah dengan mengumpulkan data-data yang diperoleh dari penelitian lapangan, peraturan-peraturan dan buku-buku yang diolah serta dianalisis dengan menggunakan metode kualitatif. Metode kualitatif merupakan tata cara penelitian yang menghasilkan data deskriptif analitis, yaitu apa yang dinyatakan oleh 
responden secara tertulis atau lisan, dan juga perilaku nyata yang diteliti dan dipelajari sebagai sesuatu yang utuh.

\section{PEMBAHASAN DAN HASIL PENELITIAN}

\section{Marketing}

Marketing adalah sebuah konsep ilmu dalam strategi bisnis yang bertujuan untuk mencapai kepuasan berkelanjutan bagi stakeholder (pelanggan, karyawan, pemegang saham). Inti dari pemasaran adalah mengidentifikasi dan memenuhi kebutuhan manusia dan sosial. Salah satu definisi yang baik dan singkat dari pemasaran adalah memenuhi kebutuhan dengan cara yang menguntungkan. Konsep pemasaran yang harus diketahui antara lain:

1) Kebutuhan adalah sebuah kondisi dimana kita merasa kekurangan atas satu barang tertentu, dan ada sebuah dorongan untuk memenuhinya. Kebutuhan adalah syarat hidup dasar manusia. Orang membutuhkan udara, makanan air, tempat tinggal, pakaian, untuk bertahan hidup;

2) Keinginan adalah kebutuhan manusia yang sudah dibentuk oleh budaya dan kepribadian individu. Strategi pemasaran yang efektif memerlukan suatu pengetahuan tentang keinginan konsumen yang ditujukan terhadap pemanfaatan barang;

3) Permintaan dalam konteks ilmu pemasaran, adalah keinginan manusia yang didukung oleh daya beli. Permintaan adalah keinginan akan produkproduk tertentu yang didukung oleh kemampuan membayar;

4) Produk adalah apa saja yang dapat ditawarkan kepada pasar agar dapat dibeli, digunakan atau dikonsumsi, yang dapat memuaskan keinginan atau kebutuhan mereka;

5) Nilai pelanggan (customer value) adalah konsep yang sentral perannya dalam pemasaran. Sebagaimana pemasaran sebagai kegiatan mengidentifikasi, menciptakan, mengomunikasikan, menyampaikan, dan memantau nilai pelanggan.

6) Biaya yaitu sesuatu atau sejumlah uang yang dikorbankan untuk mendapatkan atau memuaskan kebutuhan; 
7) Kepuasan pelanggan adalah sejauh mana manfaat sebuah produk dirasakan sesuai dengan apa yang diharapkan pelanggan;

8) Relationship marketing merupakan istilah yang erat kaitannya dengan meraih dan menjaga kepuasan pelanggan. Kita perlu terus menerus menjaga menciptakan, menjaga, dan memperkuat hubungan dengan pelanggan. Inilah yang disebut proses hubungan pemasaran (relationship marketing).

Dengan pengetahuan konsep pemasaran, pemasar akan dapat menentukan bauran pemasaran (marketing mix). Yakni product (produk) adalah kombinasi barang dan jasa yang ditawarkan kepada pasar. Pada saat hanya satu produk saja yang terlibat, keputusan harga adalah sederhana. Namun pada umumnya, sebuah lini atau bauran produk harus ditentukan harganya. Memahami komposisi bauran dan keterkaitan diantara produk tersebut adalah penting dalam penetapan strategi penentuan harga. Price (harga) adalah sejumlah uang yang harus dibayar oleh konsumen untuk mendapatkan produk. Harga merupakan sesuatu yang diserahkan dalam pertukaran untuk mendapatkan suatu barang atau jasa. Place (tempat) adalah semua kegiatan perusahaan yang mengusahakan agar produknya tersedia bagi konsumen yang dituju. Promotion (promosi) adalah semua kegiatan perusahaan/produsen untuk meningkatkan mutu produknya dan membujuk/merayu konsumen agar membeli produknya.

\section{Konsep Spritual Marketing dan Syariah Marketing}

Pemikiran spiritualisme merupakan suatu paham yang lebih menekankan pada aspek moral, kerohanian dan mengesampingkan aspek kebendaan dalam kehidupan manusia. Sedangkan pemasaran adalah proses merencanakan dan melaksanakan konsep, memberi harga, melakukan promosi dan mendistribusikan ide, barang dan jasa untuk menciptakan pertukaran yang memenuhi tujuan individu dan organisasi.

Secara umum, syariah marketing adalah sebuah disiplin bisnis strategi yang mengarahkan proses penciptaan, penawaran dan perubahan value dari inisiator kepada stakeholders-nya yang dalam keseluruhan prosesnya sesuai dengan akad dan prinsip-prinsip muamalah dalam Islam. Artinya dalam syariah 
marketing, seluruh proses baik proses penciptaan, proses penawaran, maupun proses perubahan nilai tidak boleh ada yang bertentangan dengan prinsip-prinsip syariat Islam.

Dengan kata lain spiritual marketing sebagaimana tercermin dari konsep syariah marketing adalah bagaimana seseorang mampu memberikan kebahagiaan kepada setiap orang yang terlibat dalam berbisnis, baik dari diri dirinya sendiri, pelanggan, pemasok, distributor, pemilik modal dan bahkan dari para pesaing. Seseorang harus mencintai pelanggan dan sekaligus menghargai pesaing. Konsep marketing dengan pendekatan spiritual mempunyai makna yang berkaitan dengan religius, dan disertai dengan nilai-nilai spiritual seperti keterbukaan, kejujuran, rendah hati, bisa dipercaya dan dibangun dengan tindakan-tindakan yang mulia.

Pengertian lebih luas mengenai spiritual marketing adalah bahwa makna spriritual di sini tidak selalu yang berkaitan dengan agama atau religius, tetapi juga mencakup aktivitas-aktivitas sosial dan artificial. Keinginan untuk berbagi pengalaman atau menolong masyarakat yang tidak beruntung juga termasuk dalam sisi-sisi spiritual manusia. Kebutuhan ini yang kemudian diterjemahkan oleh pemasar dalam "caused related marketing", di mana dari setiap pembelian yang dilakukan oleh konsumen sebagian dananya digunakan untuk kegiatan sosial. Manfaat "caused related marketing" bagi perusahaan adalah:

1) Meningkatkan citra perusahaan atau mereknya;

2) Menghalangi publisitas negatif;

3) Menghasilkan penjualan tambahan;

4) Meningkatkan kesadaran merek;

5) Memperluas basis pelanggannya;

6) Menjangkau segmen-segmen pasar yang baru;

7) Meningkatkan aktivitas penjualan merk dan ritel.

Spiritual marketing merupakan tingkatan pemasaran tertinggi. Seseorang tidak semata-mata menghitung lagi untung atau rugi, tidak terpengaruh lagi dengan hal-hal yang bersifat duniawi. Panggilan jiwalah yang mendorongnya karena di dalamnya mengandung nilai-nilai spiritual. Spiritual marketing adalah tingkatan "pemasaran langit", yang karena di dalam keseluruhan prosesnya tidak ada yang bertentangan dengan prinsip dan aturan syariat. Setiap langkah, aktivitas 
dan kegiatannya akan selalu seiring dengan bisikan nurani, tidak akan ada lagi hal-hal yang berlawanan dengan hati nurani. Selain itu, dalam spiritual marketing, bisnis yang disertai dengan keikhlasan semata-mata hanya untuk mencari keridhaan Allah SWT, maka seluruh bentuk transaksinya menjadi ibadah dihadapan Allah SWT. Ini akan menjadi bibit dan modal dasar baginya untuk tumbuh menjadi bisnis yang besar, yang memiliki spiritual brand, yang memiliki kharisma, keunggulan, dan keunikan yang tak tertandingi. Dalam spiritual marketing hal-hal yang sekiranya dapat merugikan konsumen akan berusaha untuk dihindarkan.

Ada empat karakteristik syariah marketing yang menjadi pedoman bagi pemasar yaitu: Pertama, Teistis (rabbaniyah), salah satu ciri khas syariah marketing yang tidak dimiliki dalam pemasaran konvensional yang dikenal selama ini adalah sifatnya yang religius. Kondisi ini tercipta tidak karena keterpaksaan, tetapi dari kesadaran akan nilai-nilai religius, yang dipandang penting dan mewarnai aktivitas pemasaran agar tidak terperosok ke dalam perbuatan yang dapat merugikan orang lain. Jiwa seorang syari'ah marketer meyakini bahwa hukum-hukum syariat Islam yang teistis atau bersifat ketuhanan ini adalah hukum yang paling adil, paling sempurna, paling selaras dengan segala bentuk kebaikan, paling dapat mencegah segala bentuk kerusakan, paling mampu mewujudkan kebenaran, memusnahkan kebatilan, dan menyebarluaskan kemaslahatan karena merasa cukup akan segala kesempurnaan dan kebaikan.

Syariah marketer harus membentengi diri dengan nilai-nilai spiritual karena marketing memang akrab dengan penipuan, sumpah palsu, riswah (suap), korupsi. Dari hati yang paling dalam, seorang syari'ah marketing meyakini bahwa Allah SWT selalu dekat dan mengawasinya ketika dia sedang melaksanakan segala macam bentuk bisnis,

dia pun yakin Allah SWT akan meminta pertanggungjawaban darinya atas pelaksanaan syariat itu pada hari ketika semua orang dikumpulkan untuk diperlihatkan amal-amalnya di hari kiamat.

Kedua, etis (akhlaqiyah), keistimewaan yang lain dari seorang syari'ah marketer selain karena teistis, ia juga sangat mengedepankan masalah akhlak (moral, etika) dalam seluruh aspek kegiatannya. Sifat etis ini sebenarnya 
merupakan turunan dari sifat teistis di atas. Dengan demikian syari'ah marketing adalah konsep pemasaran yang sangat mengedepankan nilai-nilai moral dan etika, tidak peduli apapun agamanya karena nilai-nilai moral dan etika adalah nilai yang bersifat universal yang diajarkan semua agama. Semakin beretika seseorang dalam berbisnis, maka dengan sendirinya dia akan menemui kesuksesan. Sebaliknya bila perilaku bisnis sudah jauh dari nilai-nilai etika dalam menjalankan roda bisnisnya sudah pasti dalam waktu dekat kemunduran akan ia peroleh. Oleh karena itulah, saat ini perilaku manusia dalam sebuah perusahaan yang bergerak dalam dunia bisnis menjadi sangat penting. Satu bentuk pentingnya perilaku bisnis tersebut dianggap sebagai satu masalah jika yang bersangkutan mempunyai perilaku yang kurang baik, dan dianggap bisa membawa kerugian dalam suatu perusahaan.

Ketiga, realistis (al-waqi'iyyah). Syari'ah marketing bukanlah konsep yang eksklusif, fanatik, dan kaku tetapi sangat profesional dan fleksibel dan dalam bersikap dan bergaul, Ia sangat memahami bahwa dalam situasi pergaulan di lingkungan yang sangat heterogen, dengan beragam suku, agama dan ras. Fleksibilitas sengaja di berikan oleh Allah SWT agar penerapan syari'ah senantiasa realitis dan dapat mengikuti perkembangan zaman.

Keempat, humanistis (al-insaniyyah). Keistimewaan syari'ah marketing yang lain adalah sifatnya humanistis universal. Pengertian humanistis adalah bahwa syariah diciptakan untuk manusia agar derajatnya terangkat, sifat kemanusiaannya terjaga dan terpelihara, serta sifat-sifat kehewanannya dapat terkekang dengan panduan syariah. Dengan memiliki nilai humanistis ia menjadi manusia yang terkontrol dan seimbang bukan manusia yang serakah yang menghalalkan segala cara untuk meraih keuntungan yang sebesar-besarnya. Bukan menjadi manusia yang bisa bahagia di atas penderitaan

orang lain atau manusia yang hatinya kering dengan kepedulian sosial. Syariat Islam adalah insaniyyah berarti diciptakan untuk manusia sesuai dengan kapasitasnya tanpa menghiraukan ras, warna kulit, kebangsaan dan status. Hal inilah yang membuat syariah memiliki sifat universal sehingga menjadi syariat humanitis universal. Hal tersebut dapat dikatakan prinsip ukhuwah insaniyyah (persaudaraan antar manusia). 
Terdapat tiga aspek penting dalam hal pemasaran, yaitu strategi, program dan value. Akan tetapi meskipun marketer mempunyai strategi-strategi yang briliant, program yang cerdas, eksklusif dan value yang kompetitif bukan jaminan bahwa tawaran produk itu akan sukses dan menguasai pangsa pasar. Ketiga aspek itu perlu dukungan dari soul marketing, dimana dalam soul marketing terdapat tiga aspek pendukung, yaitu mind share, marketing share, dan heart share sebagai faktor utama dalam mendapatkan trust dari customer sehingga secara tidak langsung akan mendapatkan revenue yang diinginkan.

\section{Strategi Marketing}

Strategi yang dirancang untuk memenangkan customer mind (mind) share, merketer harus mampu melakukan segmentasi, menetapkan target, dan memposisikan produk secara tepat dibenak konsumen yang lebih baik dari kompetitor. Strategi dijelaskan sebagai arah yang dituju oleh sebuah perusahaan (dalam hal ini FEBI Unsur) dan menuntun pada pengalokasian sumber daya. Namun yang perlu diperhatikan bahwa sasaran utama dari strategi ini adalah persepsi konsumen, jadi persaingan sebenarnya bukan merebut pangsa pasar, melainkan untuk mendapatkan persepsi dalam benak masyarakat. Apabila perepsi tersebut sudah didapat, maka secara tidak langsung pangsa pasar akan ada dalam genggaman.

\section{Segmentasi}

Cara membagi pasar pada variabel-variabel tertentu seperti faktor geografi, demografi, psikologi, perilaku dan akhirnya pada varabel terkecil, yaitu individu. Dalam hal ini, yang dapat dijadikan segmentasi oleh FEBI adalah seluruh lulusan SMA/sederajat se-Kabupaten Cianjur yang beragama Islam, dan mempunyai keinginan untuk memilih jurusan Ekonomi Syariah, Perbankan Syariah dan Akuntansi Syariah.

Sebagian besar masyarakat Cianjur adalah muslim, sehingga potensi calon mahasiswa yang memilih prodi-prodi di FEBI akan lebih besar. Hal ini, dapat dikaitkan dengan maraknya isu tentang perkembangn sistem Ekonomi dan Perbankan Syariah. Selain itu, FEBI merupakan satu-satunya fakultas yang 
mempunyai jurusan Ekonomi Syariah dan Perbankan yang ada di Kabupaten Cianjur. Ini merupakan nilai tambah tersendiri bagi FEBI.

\section{Target}

Proses pemilihan target dan mencocokan reaksi pasar dengan kebutuhan dasar, kemampuan daya beli dan keterbatasan yang dimiliki. FEBI dapat menjadikan lulusan SMA/sederajat se Kabupaten Cianjur yang beragama Islam, beretika baik, dan yang ingin melanjutkan ke jenjang yang lebih tinggi sebagai target marketnya.

\section{Positioning}

Bagaimana menempatkan produk anda kedalam benak cutomer secara luas sehingga akan tertanam dalam benak pasar bahwa perusahaan anda adalah definisi dari kategori produk yang anda jual. Dengan bekal sistem pengajaran yang berbeda, mahasiswa diajarkan pada dua disiplin ilmu (konvensional dan syariah) dan penekanan etika, moral, dan spiritual pada diri mahasiswa. Sistem seperti ini dapat memberikan point of different bagi mahasiswa FEBI dibandingkan dengan jurusan lain. Selain itu, mahasiswa dengan etika dan moral yang bagus akan memperlihatkan keanggunan dalam bersosialisasi, sehingga orang akan mempersepsikan berbeda dengan mahasiswa jurusan lain.

\section{Program Marketing}

Ada juga yang menyebutnya dengan istilah taktik. Komponen program pemasaran terdiri atas: product, price, place, promotion, differentation, dan selling (4PDS). Aspek ini merupakan alat untuk menguasai market share. Pangsa pasar dalam Islam terbagi tiga, yakni pasar rasional, emosional, spiritual.

\section{Product}

FEBI Unsur merupakan satu-satunya Fakultas Ekonomi dan Bisnis Islam yang ada di Kabupaten Cianjur, sehingga untuk masalah kualitas dan harga sangat terjangkau oleh semua kalangan. Dan kredibilitasnya sangat diakui. 


\section{9. $\quad$ Price}

Biaya kuliah yang semakin mahal menyebabkan banyak masyarakat yang lebih memilih untuk bekerja sebagai pilihan hidupnya. Sistem pembayaran di FEBI sangat memperhatikan kondisi keuangan mahasiswa. Sehingga, mahasiswa secara bebas bisa menyicil uang kuliahnya kapan pun selama perkuliahan tiap semester belum berakhir dengan biaya perkuliahan yang sangat terjangkau bagi setiap kalangan.

\section{Place}

FEBI bertempat di komplek Universitas Suryakancana jalan Pasir Gede Raya, Cianjur, yang merupakan tempat strategis dan nyaman yang dipergunakan untuk belajar. Sarana dan prasarana yang menunjang pendidikan cukup memadai.

\section{Promotion}

Dalam hal ini, FEBI melakukan promosi pada dua sektor. Pertama sektor fakultas, dimana pada sektor ini para pengajar atau dosen menyiapkan program khusus untuk memasarkan prodi Ekonomi Syariah, Perbankan Syariah dan Akuntansi Syariah. Dosen-dosen pilihan dan berkualitas, tidak hanya pada soal ekonomi dan pendidikan melainkan juga soal etika, moral dan spiritual yang setiap hari mereka ajarkan dan mereka imlementasiakan kepada masyarakat, memberikan nilai lebih pada persepsi masyarakat. Kedua, sektor Himpunan Mahasiswa (HIMA), mereka membuat program-program dengan target siswa SMA, seperti olimpiade SMA se-Kabupaten Cianjur, Seminar Ekonomi Syariah, Buletin yang di bagi secara free kepada siswa SMA. Dalam melakukan kegiatanya, HIMA sangat terlihat mencerminkan sikap sopan santun, beretika, berakhlak baik sehingga dapat dijadikan panutan bagi yang melihatnya, dan secara tidak langsung menjadi investasi ke dalam benak konsumen kalau mahasiswa FEBI berakhlak baik. Diharapkan orang tua menentukan pilihan untuk anaknya agar memilih prodi-prodi yang ada di FEBI. 


\section{Selling}

FEBI tidak akan membujuk ataupun memaksa calon mahasiswa untuk bergabung, tapi FEBI selalu mikirkan bagaimana agar FEBI itu di kenal dalam benak masyarakat. Sehingga, diharapkan orang tua menentukan pilihan untuk anaknya agar memilih prodi-prodi yang ada di FEBI.

\section{Value marketing}

Nilai yang dipersepsikan pelanggan terhadap tawaran kualitas produk, service dan brand jika value ini bagus, maka kegiatan pemasaran dapat memperoleh heart share dari pelanggan. Masyarakat mengetahui bahwa FEBI merupakan satu-satunya Fakultas Ekonomi dan Bisnis Islam yang berada di wilayah Kabupaten Cianjur. Sehingga untuk masalah kualitas dan kredibilitasnya sangat diakui. Hal ini, bisa dimanfaatkan dengan baik untuk meningkatkan jumlah mahasiswa dari tahun ke tahun.

\section{Soul marketing}

Komunikasi secara masal (pendaftaran perguruan tinggi) terbukti tidak efektif untuk menjaring calon mahasiswa baru untuk memilih prodi-prodi di FEBI. Hal ini terbukti masih banyak masyarakat yang belum mengetahui prodiprodi apa saja yang ada di FEBI. Sebagai mahasiswa dan dosen diharapkan mampu melakukan komunikasi yang benar kepada masyarakat melalui programprogram pengenalan, etika dalam bersosialisasi, sopan santun, dan rasa bangga. Dengan adanya FEBI bisa dijadikan sebagai magnet untuk mengubah persepsi mayarakat akan perkembangan Ekonomi Syariah, Perbankan Syariah dan Akuntansi Syariah. Tentunya, program-program tersebut dijalankan atas keikhlasan dan selalu memohon ridho Allah SWT.

\section{Mind share}

Dosen dan mahasiswa merupakan komponen utama dalam memberikan pengenalan dengan FEBI kepada masyarakat dengan menggunakan pendekatan spitual marketing. Karena, secara tidak langsung masyarakat akan menilai seberapa jauh dampak sistem pengajaran yang diimplentasikan kepada mahasiswa 
apalagi implementasi pada aspek penekanan etika, moral, dan spiritual pada diri mahasiswa berpengaruh terhadap perilaku mereka di masyarakat. Apabila pandangan masyarakat kepada kita positif, maka kita akan mendapatkan tempat di benak konsumen. Hal ini menimbulkan trust dan dalam jangka panjang akan mendapatkan wallet share.

\section{Marketing share}

Untuk menguasai persepsi masyarakat tentang baiknya FEBI, maka diharuskan mempunyai strategi-strategi yang berbeda dan brilliant dalam pengembangan pola pikir mahasiswa. Salah satunya adalah differentation dengan jurusan-jurusan yang lain dengan penekanan kepada aspek etika, moral, dan spiritual pada diri mahasiswa.

\section{Heart share}

Nilai tambah dengan muatan emosi yang tinggi adalah senjata utama untuk merebut heart share. Pentingnya penguasaan heart share menjadi strategi selanjutnya setelah kita menaklukan mind share dan marketing share. Universitas Suryakancana mempunyai brand image yang sangat dikenal oleh masyarakat luas khususnya di Kabupaten Cianjur karena Universitas Suryakancana merupakan kampus terbesar di Kabupaten Cianjur. Akan tetapi personal brandnya yaitu FEBI tidak sebesar Unsur, hal ini terjadi karena FEBI merupakan fakultas baru, yang berdiri pada tahun 2016. Akan tetapi setelah merebut pangsa mind dan market share, secara simultan personal brandnya juga akan meningkat.

\section{KESIMPULAN}

Praktek implementasi spiritual marketing dalam upaya memasarkan prodi Ekonomi Syariah pada Fakultas Ekonomi dan Bisnis Islam Universitas Suryakancana sangat dianjurkan, mengingat dampak dari penerapannya sangat menguntungkan baik dunia maupun akhirat. Secara tidak langsung para pemasar sudah melakukan ibadah dan mengimplementasikan akhlak, etika, dan spiritual yang sangat bagus yang didapat pada saat pembelajaran, mengingat keuntungan seperti ini tidak didapat di sistem pemasaran lainnya. Dari sisi customer (calon 
mahasiswa dan masyarakat) menjadi lebih memahami tentang prodi Ekonomi

Syariah, Perbankan Syariah dan Akuntansi Syariah, serta baik dan

buruknya dalam bertindak, karena saat marketer bekerja, mereka menjadi tauladan bagi customer karena tingkah lakunya yang sesuai syariah. Disamping itu akan tumbuh rasa loyalitas dan trust pada benak masyarakat akan kredibilitas terhadap FEBI. Adapun keuntungan dalam jangka panjang FEBI akan memperoleh wallet share dari siklus spiritual marketing yang dapat digunakan sebagai modal pengembangan ekonomi syariah kedepannya.

\section{REFERENSI}

Afzalur Rahman. 1995. Doktrin Ekonomi Islam. Yogyakarta: PT. Dana Bhakti Wakaf.

Ali Hasan. 2009. Marketing. Yogyakarta: PT. Buku Kita.

Amir M. Taufiq. 2005. Dinamika Pemasaran. Jakarta: PT. Raja Grafindo Persada.

Basu Swastha dan Irawan. 2003. Menejemen Pemasaran Moderen. Yogyakarta: Liberty Yogyakarta.

Carl McDaniel and Roger Gates. 2001. Contemporary Marketing Research. Terj. Sumiyarto dan Rambat Lupiyoadi. Riset Pemasaran Kontemporer. Jakarta: Salemba Empat.

Henry Simamora. 2000. Manajemen Pemasaran Internasional. Jakarta: Salemba Empat.

Hermawan Kertajaya dan Muhammad Syakir Sula. 2006. Syariah Marketing. Bandung: Mizan Pustaka.

Husaeni, Uus Ahmad. (2017). The Influence of Marketing Mix on Decision to be a Islamic Banking Customer in Cianjur Regency. IQTISHADIA. Vol.10 No. 2, pp. 105-119.

Johan Arifin. 2007. Fiqih Perlindungan Konsumen. Semarang: Rasail.

Lamb, Hair, McDaniel. 2000. Pemasaran. Jakarta: Salemba Empat.

Philip Kotler dan Kevin Lane. 2009. Manajemen Pemasaran. Jakarta: Erlangga.

Rivai Veithzal. 2012. Islamic marketing. Jakarta: PT.Gramedia Pustaka Utama.

Soerjono Soekanto. 2006. Pengantar Penelitian Hukum, Jakarta: Universitas Indonesia Press.

Suharsimi Arikunto. 2004. Prosedur Penelitian Suatu Praktik, Jakarta: Bina Aksara.

Triana, Setiyarini, Pemasaran Spiritual Sebagai Strategi Memenangkan Persaingan Melalui Komunitas Spiritual, dalam Jurnal Studi Manajemen, Vol. 3, No. 2 Oktober 2009. 